\title{
Immune modulation by chronic exposure to waterpipe smoke and immediate-early gene regulation in murine lungs
}

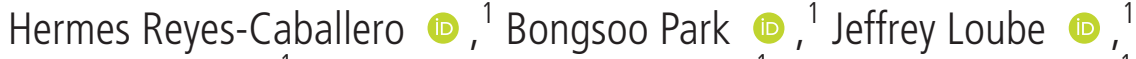

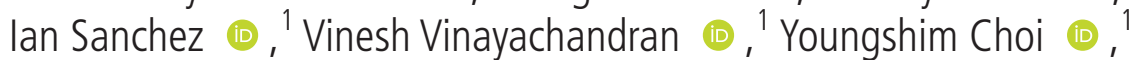 \\ Juhyung Woo (1) , ${ }^{1}$ Justin Edwards, ${ }^{1}$ Marielle C Brinkman 이, , Thomas Sussan (1), ${ }^{3}$ \\ Wayne Mitzner 다, 'Shyam Biswal 이 ${ }^{1}$
}

\begin{abstract}
- Additional material is published online only. To view please visit the journal online (http://dx.doi.org/10. 1136tobaccocontrol-2019054965).
\end{abstract}

${ }^{1}$ Environmental Health and Engineering, Johns Hopkins University, Baltimore, Maryland, USA

${ }^{2}$ College of Public Health, The Ohio State University, Columbus, Ohio, USA ${ }^{3}$ Toxicology Directorate, US Army Public Health Command, Aberdeen Proving Ground Maryland, USA

\section{Correspondence to}

Dr Hermes Reyes-Caballero and Dr Shyam Biswal, Environmental Health and Engineering, Johns Hopkins University, Baltimore, MD 21205, USA;

hreyesc1@jhu.edu, sbiswaljh@ gmail.com

Received 25 January 2019 Revised 22 August 2019 Accepted 24 August 2019 Published Online First 18 December 2019

\begin{abstract}
Objective We investigated the effects of chronic waterpipe (WP) smoke on pulmonary function and immune response in a murine model using a researchgrade WP and the effects of acute exposure on the regulation of immediate-early genes (IEGs).
\end{abstract}

Methods WP smoke was generated using three WP smoke puffing regimens based on the Beirut regimen. WP smoke samples generated under these puffing regimens were quantified for nicotine concentration. Mice were chronically exposed for 6 months followed by assessment of pulmonary function and airway inflammation. Transcriptomic analysis using RNAseq was conducted after acute exposure to characterise the IEG response. These biomarkers were then compared with those generated after exposure to dry smoke (without water added to the WP bowl).

Results We determined that nicotine composition in WP smoke ranged from 0.4 to $2.5 \mathrm{mg}$ per puffing session. The lung immune response was sensitive to the incremental severity of chronic exposure, with modest decreases in airway inflammatory cells and chemokine levels compared with air-exposed controls. Pulmonary function was unmodified by chronic WP exposure. Acute WP exposure was found to activate the immune response and identified known and novel IEG as potential biomarkers of WP exposure.

Conclusion Chronic exposure to WP smoke leads to immune suppression without significant changes to pulmonary function. Transcriptomic analysis of the lung after acute exposure to WP smoke showed activation of the immune response and revealed IEGs that are common to WP and dry smoke, as well as pools of IEGs unique to each exposure, identifying potential biomarkers specific to WP exposure.

\section{INTRODUCTION}

Waterpipes (WPs), also known as hookah, have been used for centuries in the Eastern Mediterranean region and parts of Asia and Africa. ${ }^{1}$ However, the popularity of WP smoking has seen a dramatic surge in recent years in the USA and abroad, particularly among young adults. ${ }^{2}$ In the USA alone, the prevalence of WP use among youths increased from 7\% to $12 \%$ between 2010 and $2015 .{ }^{4}$ Moreover, despite successful legislative bans on indoor smoking in many countries, most indoor smoking legislation exempts or does not enforce these bans on WP establishments. ${ }^{5}$
Thus, WPs represent an emerging alternative tobacco product that may pose significant risks to public health, particularly among young individuals.

Contrary to common misconception, serious health effects are related to WP use. Epidemiological studies have shown that WP smoking is associated with increased risks of cardiovascular diseases, ${ }^{6}$ cancer (lung, oesophageal, head and neck, and gastric), ${ }^{7-10}$ metabolic syndrome ${ }^{11}$ and chronic obstructive pulmonary disease (COPD). ${ }^{12}$ An additional health risk that is of particular concern for young adults is nicotine dependence, and similar to any other tobacco product is represented in WP smokers by substance addiction behaviours. ${ }^{13-19}$ In agreement with the health risks identified to date, analytical examination of the components in WP smoke include a mixture of chemicals with known or suspected disease-causative agents that closely resemble those found in cigarette smoke (CS), and in many cases at higher concentrations. $^{20}{ }^{21}$ Indeed, WP is estimated to deliver to cells and tissues a similar group of toxicants that are known to dysregulate cell molecular mechanisms, including DNA repair and methylation. ${ }^{22-26}$ Herein, we investigated the effects of lung health using a murine model by analysing inflammation and pulmonary function after chronic WP exposure for 6 months. On the basis of the scarcity of papers published on this topic, the exposure length of 6 months is rarely studied. Thus, the current study unveiled the modulation of immunological response after chronic WP exposure.

Biomarkers of tobacco use are predictors of molecular changes that precede toxicological health outcomes. ${ }^{27}$ These biomarkers provide information to policymakers during the assessment of health risks associated with new and modified tobacco products. $^{28}$ Several biomarkers exist for conventional tobacco products; however, biomarkers specific for WP, smokeless tobacco products or other modified-risk tobacco products have not been well established. ${ }^{29}{ }^{30}$ We report, for the first time, the differential expression of immediate-early genes (IEG) upregulated in the lung after acute exposure to WP and dry smoke (with no water in the bowl). The IEGs identified in this study are potential biomarkers of exposure to WP.

\section{METHODS \\ WP smoke}

WP smoke was generated via a research-grade WP fabricated by Battelle as described previously. ${ }^{31}$ 


\begin{tabular}{lrrrr}
\hline Table 1 & Waterpipe puffing regimens & & \\
\hline Regimen & Low & Modified Beirut & High & Beirut $^{32}$ \\
\hline Puff volume (mL) & 300 & 530 & 750 & 530 \\
\hline Puff duration (s) & 3 & 3 & 3 & 2.6 \\
Puff interval (s) & 18 & 18 & 18 & 17 \\
\hline Puffs per session & 171 & 171 & 171 & 171 \\
\hline Session duration (min) & 60 & 60 & 60 & 61 \\
\hline Mean puff flow (L/min) & 6 & 10.6 & 15 & 12.2 \\
\hline Total volume (L)* & 51.3 & 90.6 & 128.25 & 90.6 \\
\hline
\end{tabular}

${ }^{*}$ Total volume per session.

Before each exposure, $1400 \mathrm{~mL}$ fresh water was added to the WP bowl tank, and $12-13 \mathrm{~g}$ shisha was added to the head. Subsequently, the head was covered with aluminium foil, and a lit $40 \mathrm{~mm}$ charcoal (Al Fakher) was placed on top. At $10 \mathrm{~min}$ postlighting, the WP was puffed according to specific regimens using a connected peristaltic pump. After $40 \mathrm{~min}$, the charcoal was replaced by an identical charcoal. Dry smoke was generated using a setting similar to that for WP smoke, without the addition of water to the bowl. The shisha products used are commercially available Blue mint (product 1 , a minted product) and Exotic Pirate's Cave (product 2) from Starbuzz. A diagram of the WP setting is provided in online supplementary figure 1 .

\section{Puffing regimens}

WP smoke was generated with one of three different puffing regimens. The regimens were based on the Beirut puffing regimen. ${ }^{32}$ For this study, a modified Beirut regimen was executed with a peristaltic pump (table 1). Additionally, 'high' and 'low' puffing regimens were generated, as described in table 1.

\section{Mouse exposure}

The source and strain of mice (C57BL/6J, female mice, 6-7 weeks old and $19 \mathrm{~g}$ average weight) used in all experiments were purchased from Jackson Laboratory. WP smoke was generated as described in table 1 and was mixed with filtered dilution air at a flow rate of $10 \mathrm{~L} / \mathrm{min}$. Animals were exposed to WP smoke for 1 hour/day, 5 days/week for 6 months in a nose-only exposure chamber (Jaeger-Baumgartner). Body weight measurements used a digital plate balance to monitor weight change at 1,2, 4 and 6 months in the mice used for chronic exposure to product 2. Online supplementary table 1 shows the sample number (n) and the exact duration for each experiment.

\section{TPM collection and nicotine measurements}

For the analysis of the nicotine content of WP smoke, we used a previously described method with few modifications. ${ }^{33}$ Briefly, total particulate matter (TPM) of WP smoke was collected (product 2) on a Cambridge filter pad (CFP) $(47 \mathrm{~mm}$ diameter PSI borosilicate glass depth media, 1-2 $\mu \mathrm{m}$ ) located inside an aluminium housing hooked to the mouse exposure chamber. Product 1 was not measured. For nicotine analysis of the mainstream smoke, the CFP was sampled for $30 \mathrm{~min}$ at a high puffing regimen, without the dilution air injection and with the peristaltic pump for sampling set at $2 \mathrm{~L} / \mathrm{min}$. To obtain a good signal to noise ratio for the mass spectroscopic analysis, we concentrated two more exposures to the same CFP using the following procedure. The CFP was left in the aluminium housing equilibrated to room conditions overnight, and the exposure was repeated for two additional 24-hour periods. Three replicates $(n=3)$ were collected for the analysis as described above. Gravimetric analysis was performed to determine the TPM masses by calculating the weight difference of the CFP before and after smoking. The average $( \pm$ SD) TPM per exposure for nicotine analysis was $3339(715) \mathrm{mg} / \mathrm{m}^{3}$, and the mean weight difference of the CFP was 482 (141) mg. The TPM was then extracted with $20 \mathrm{~mL}$ of extraction solution (isopropyl alcohol containing approximately $0.1 \mathrm{mg} / \mathrm{mL}$ anethole internal standards) with gentle shaking at 160 revolutions per minute (rpm) for $30 \mathrm{~min}$. Extracts were analysed for nicotine using gas chromatography-flame ionisation detection. Calibration curves were constructed with 10 different analyte concentrations ranging from 0.004 to $1.0 \mathrm{mg} / \mathrm{mL}$. Quantification was determined using area ratios of the analyte-tointernal standard with a linear, least-squares fit to the calibration curve. Nicotine mass ratio refers to the total nicotine divided by the total suspended particle (TSP), as previously defined. ${ }^{34}$

\section{TSP collection}

For all exposures, TSP was collected daily to a CFP throughout the entire $60 \mathrm{~min}$ exposure using a peristaltic pump that sampled the exposure chamber at $0.4 \mathrm{~L} / \mathrm{min}$. For the acute exposure, TSPs were sampled for 5 days in the mouse exposure chamber according to the same experimental conditions used for the acute 1-hour exposures. TSP data are presented in table 2.

\section{Airway inflammation}

Mice were euthanised approximately 24 hours after the final WP exposure. Bronchoalveolar lavage (BAL) was performed, and cell-free supernatants were used for cytokine analysis, as described previously. ${ }^{35}{ }^{36}$ Total cell counts from BAL were quantified via an automatic cell counter (Adam MC, Bulldog Bio) and differential cell counts were determined via microscopic evaluation of cytospin preparations (Thermo Fisher) according to standard cytological criteria. ${ }^{37}$ Total cell counts in the air control groups of product 1 and product 2 did not differ statistically. Online supplementary table 2 contains statistics and biological replicas.

\section{Cytokine and chemokine detection}

Inflammatory cytokines were quantified in BAL samples using a chip assay based on Luminex Technology (Luminex Corporation) and Milliplex panel kit MCYTOMAG-70K (MilliporeSigma); this allowed the simultaneous testing of 32 analytes. The standard protocol of Milliplex panel was employed, with a few exceptions. Briefly, $15 \mu \mathrm{L}$ of BAL sample was used, and the incubation period was increased to 16 hours in a cold room. Samples were randomly positioned on a 96-well plate. The Curiox (Curiox Biosystems) wash system was used on plates, as reported previously. ${ }^{38} 39$

\section{Lung function}

Mice were anaesthetised with a ketamine $(90 \mathrm{mg} / \mathrm{kg})$-xylazine $(18 \mathrm{mg} / \mathrm{kg})$ mixture. Once sedated, tracheostomy was performed, and an 18-gauge cannula was inserted. Diffusing capacity for carbon monoxide (CO) was then measured using the singlebreath method as described. ${ }^{40}{ }^{41}$ For pressure-volume (PV) curves, after diffusion factor for carbon monoxide (DFCO) was measured, mice were connected to a flexiVent ventilator as described previously. ${ }^{42}$ DFCO measurement is an indication of lung function similar to diffusion capacity of the lung for carbon monoxide (DLCO). This diffusing capacity metric is dimensionless, varying between 0 and 1 , where 0 reflects no $\mathrm{CO}$ uptake and 1 reflects complete CO uptake. Sampling pure alveolar gas is not feasible in the mice. Sampled gas includes the small 
Table 2 TSP recorded during exposure experiments in the mouse nose-only exposure chamber

\begin{tabular}{lll}
\hline Regimen & $\begin{array}{l}\text { Product 1 TSP* }(\mathrm{mg} / \\
\left.\mathrm{m}^{3}\right) \pm S D\end{array}$ & $\begin{array}{l}\text { Product } 2 \mathrm{TSP} *(\mathrm{mg} / \\
\left.\mathrm{m}^{3}\right) \pm \text { SD }\end{array}$ \\
\hline $\begin{array}{ll}\text { Chronic exposure (6 months) } \\
\text { Low }\end{array}$ & $330 \pm 064$ & $317 \pm 35$ \\
$\quad$ Modified Beirut & $644 \pm 141$ & $521 \pm 40$ \\
$\quad$ High & $827 \pm 155$ & $743 \pm 76$ \\
Acute exposure (1 hour) & & \\
$\quad$ WP & ND & $560 \pm 133$ \\
\hline Dry smoket & ND & $654 \pm 307$ \\
\hline
\end{tabular}

ND means product 1 was not tested.

*Mean TSPs of daily measures taken through each 1-hour exposure session according to product and puffing regimen.

tMean TSP for WP smoke generated without water in the bowl (dry smoke). TSP includes all particulates and water from the smoke. For WP mainstream smoke, we found that water weight accounts for $57 \%( \pm 13, S D ; n=4)$ of the total filter weight, which was used as a correction factor for nicotine quantification.

TSP, total suspended particle; WP, waterpipe.

amount of gas found in the anatomical dead space that changes the quantitative values compared with DLCO. However, because the volume of the dead space is relatively constant in a group of mice that are biologically similar, it does not alter the ability to detect changes in gas diffusion in a host of lung pathologies. Changes in DFCO have been reliably measured in mice with fibrosis, emphysema, cystic fibrosis, influenza and acute lung injury. ${ }^{40} 41$ Quasi-static PV curves were performed as previously reported. ${ }^{42}$ Because mouse lungs never reached a true maximal lung volume, ${ }^{43}$ we opted to define lung capacity $\left(\mathrm{V}_{35}\right)$ as the volume from the second inflation curve at $35 \mathrm{~cm} \mathrm{H}_{2} \mathrm{O}$, a pressure beyond which all mouse strains show progressive stiffening. Quasi-static compliance of the respiratory system was computed from the PV relationships as the slope of the deflation limb between 3 and $8 \mathrm{~cm} \mathrm{H}_{2} \mathrm{O}$, which is where the curves are most linear. Lung function was tested in mice exposed to product 2 for 6 months, as described above. The following were the replicas per regimen (n): filtered air (18), low (19), modified Beirut (20) and high (20).

\section{RNAseq analysis}

We built an index sequence for STAR using the Gencode M13 reference. $^{44}$ A total of 50600 genes were identified. Before sequence alignment, we applied trim_galore (V.0.4.3) with the cutadapt package (V.1.12). We mapped raw sequencing reads to the mouse reference genome (mm10) using STAR aligner and calculated the raw count using feature Counts package. To test reproducibility and examine outlier samples, we conducted principal component analysis before conducting a differentially expressed gene (DEG) analysis. We generated a gene-by-sample matrix of reading counts that were analysed using edgeR after removing unwanted variation $(\mathrm{RUVg}) .{ }^{45}$ The output of this analysis is a set of genomic regions that are significantly different between the experimental groups. Correction for multiple hypothesis testing was accomplished using Benjamini-Hochberg false discovery rate (FDR) with FDR $<0.05$ as the cut-off. Due to the small number of biological replicates $(n=3, W P$ and Air; $\mathrm{n}=2$, dry smoke), we used the limma-based edgeR method to determine DEGs. ${ }^{46}$

\section{Acute exposure}

Individual mice were exposed to product 2 for precisely 1 hour and then were euthanised immediately via carbon dioxide inhalation. Blood was collected using cardiac puncture. The lung was rinsed using phosphate buffer saline (PBS) similar to the procedure in BAL. Systemic perfusion was performed through a cardiac puncture injection of $30 \mathrm{~mL}$ of PBS. The lungs were collected and fast frozen. The elapsed time from euthanasia to lung collection for each mouse was around $6 \mathrm{~min}$. The frozen lung was later homogenised via a Freezer Mill (Spex 6775), using two cycles of $5 \mathrm{~s}$. The ground samples were not allowed to thaw until RNA extraction, which was performed using the Qiagen AllPrep DNA/RNA Mini Kit. Purified RNA was sent to Novogene for RNAseq procedures using an Illumina platform to a standard of 40 million reads and specific strand libraries. RNAseq analysis with Ingenuity Pathway Analysis (IPA) (Qiagen) used data of DEGs filtered by $\log _{2}$ fold change at a cut-off of \pm 1.2 , and pathway analysis filtered by direct experimental evidence from experiments in lung tissue, lung cells, cancer lung cells, immune cells, fibroblast, fibroblast cancer, immune cells and cancer immune cells. Online supplementary table 1 shows the sample number (n) and the exact date of the experiment $(\mathrm{n}=5$, filtered air, WP and dry smoke).

\section{RESULTS}

\section{Chronic exposure to WP smoke does not affect weight gain}

The puffing regimens selected for the 6-month exposure were generally well tolerated by mice. In the low regimen group, one animal died during WP exposure from product 2 over the study period (online supplementary table 1). After 6 months of exposure to product 2 , animal body mass was $23.0 \mathrm{~g}( \pm 0.5 \mathrm{SD})$, a finding consistent with data provided by the supplier. Linear regression of weight gain (product 2) showed that all groups gained weight at similar rates when an experimental error is considered (online supplementary figure 2 and online supplementary table 3 ).

\section{Nicotine exposures were similar to those of WP users}

The Beirut puffing regimen was selected as it is the average smoking topography of WP use observed in humans smoking WP in a café environment in Lebanon, ${ }^{32}$ and agrees with subsequently conducted research. ${ }^{47}$ The high and low regimens were designed to flank the Beirut regimen. The TSPs from the three regimens were between 300 and $800 \mathrm{mg} / \mathrm{m}^{3}$ (table 2), and each regimen showed similar values for both products 1 and 2, without significant differences in the TSPs. Nicotine quantification of the WP smoke from product 2 was measured to serve as a marker of exposure and a reference to estimate nicotine in product 1 . We obtained the fraction of nicotine from the TPM collected during three consecutive exposures of WP smoke without any dilution air and computed the mass ratio (table 3; the procedure is described in detail in the Methods section).

The product of the nicotine mass ratio and the mass collected on the filter during exposure, corrected for water incorporated from the smoke (57\%), was used to determine the nicotine delivered during exposure to product 2 (table 4 ). We estimated the exposure to nicotine in product 1 , assuming similar nicotine

\begin{tabular}{llll} 
Table 3 & \multicolumn{4}{l}{ Nicotine content in WP mainstream * } \\
\hline & Nicotine $(\mathrm{mg})$ & TPM $(\mathrm{mg})$ & Mass ratio \\
\hline Mean & 3.8 & 608.4 & 0.006 \\
\pm SD & 0.5 & 32 & 0.001
\end{tabular}

*Nicotine quantification in WP smoke from filter pads: $n=3$ for product 2; product 1 was not measured.

TPM, total particulate matter; WP, waterpipe. 
Table 4 Total nicotine measured by exposure in each puffing regimen

\begin{tabular}{llll}
\hline & \multicolumn{3}{l}{ Nicotine per regimen $(\mathrm{mg}) \pm \mathrm{SD}^{*}$} \\
\cline { 2 - 4 } Shisha & Low & Modified Beirut & High \\
\hline Product 1 & $0.41 \pm 0.36$ & $1.4 \pm 0.20$ & $2.5 \pm 0.12$ \\
Product 2 & $0.39 \pm 0.17$ & $1.1 \pm 0.09$ & $2.3 \pm 0.09$
\end{tabular}

*SD calculated by error propagation. Estimated values for product 1 based on nicotine analysis of product 2 .

concentrations in products 1 and 2. The mass of nicotine in WP smoke diluted with the filtered air used for mice during the exposure was between 0.4 and $2.5 \mathrm{mg}$, agreeing with those values reported in other studies, which showed that the nicotine supplied during a typical smoking session is between 0.32 and $7.8 \mathrm{mg} .{ }^{48-50}$

\section{Chronic exposure decreases lymphocyte counts in BAL fluid}

We investigated whether the puffing regimens elicit a dysregulation of the immune cells. Hence, a quantitative analysis of the number of inflammatory cells, including lymphocytes, macrophages and neutrophils, was conducted using differential cell counts of BAL. The BAL samples examined for cell counts of mice exposed for 6 months showed that the number of lymphocytes showed a tendency to decrease according to the intensity of the puffing regimen for products 1 and 2, and in most cases were significantly lower than the filtered air controls (figure 1A,D). In contrast to lymphocytes, macrophages remained unchanged compared with air controls for both products 1 and 2 (figure 1B,E). In most cases, the high variability in the number of neutrophils masked meaningful declines (figure 1C,F). Lack of a robust immune response, with plausible immunosuppression, was observed at 6 months for products 1 and 2 .

\section{Chronic exposure decreases CXCL9, CXCL10 and CCL11 in BAL fluid}

To further understand the decreased immune response after chronic WP exposure, we quantified a broad array of cytokines/chemokines in the cell-free BAL fluid from the mice that showed immunosuppression after 6 months of WP smoke using product 2 . Luminex-based analysis of 32 cytokines revealed that across the panel tested, the levels of most cytokines remained unchanged after 6 months of exposure. However, C-X-C Motif Chemokine Ligand 9 (CXCL9 or MIG), C-X-C Motif Chemokine Ligand 10 (CXCL10 or IP-10) and C-C Motif Chemokine Ligand 11 (CCL11 or eotaxin) were significantly reduced for some of the exposure regimens, without a marked correlation with the puffing regimens (figure 2). CXCL10 and CXCL9 are chemokines produced in response to CS. They bind to receptors that are mainly expressed on $\mathrm{T}$ lymphocytes, powerfully attracting other cells from the innate and adaptive immunity. ${ }^{51-54}$ CCL11 attracts eosinophils that are important for the development of lung airway hyper-responsiveness in asthma and allergies. ${ }^{55}$ The current results showed minimal stimulation of the immune response, with key cytokines for inflammation during CS exposure significantly reduced in the exposure to product 2 .
A

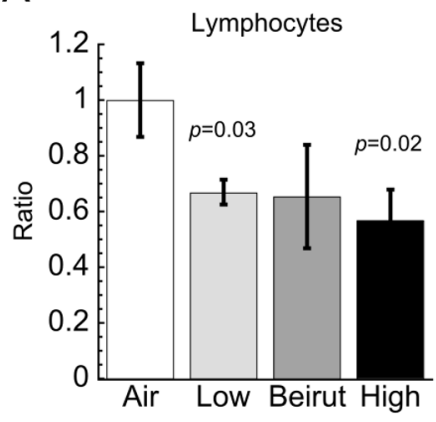

D

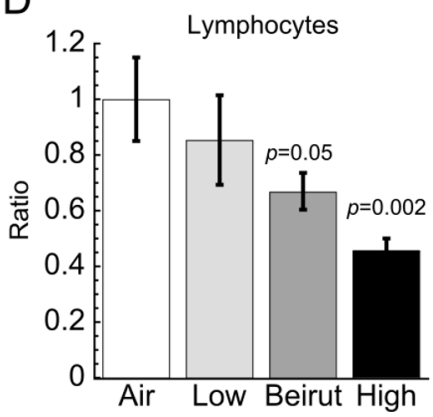

B

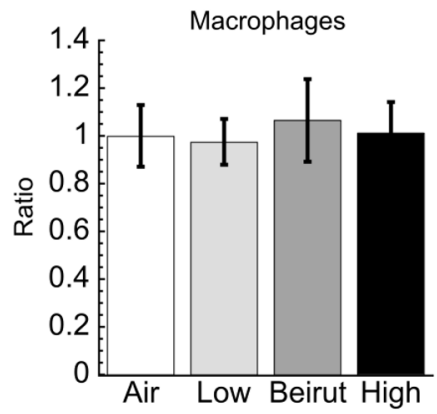

E

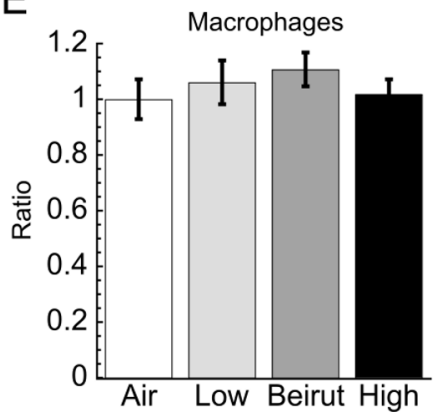

C

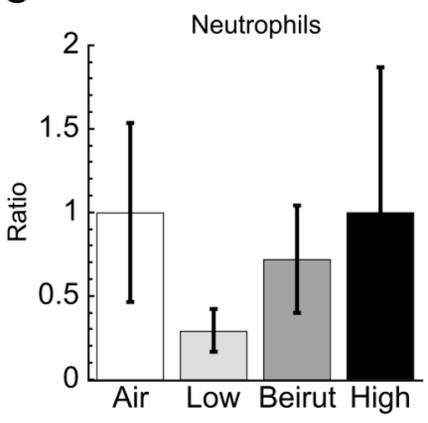

$\mathrm{F}$

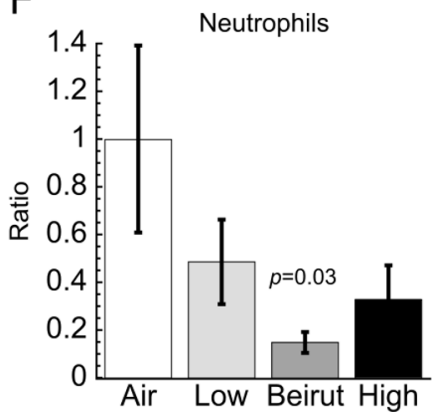

Figure 1 Quantification of inflammatory cells in bronchoalveolar lavage from mice exposed for 6 months to three regimens of waterpipe mainstream smoke. Ratios indicate the relative changes in the normalised cell counts (cells $/ \mathrm{mL}$ ) for each regimen using filtered air control (Air) as reference. Shown are the results of two shisha products: (A-C) product 1; (D-F) product 2. Beirut: modified Beirut; Air: filtered air control group. Error bars represent SE. We assumed an equal variance in the distribution to apply a Student's t-test with an alpha level set to 0.05 . The $p$ values above the bars denote significant changes. Oonline supplementary table 2 reports the total cell counts, normalised cell counts, number of replicas and the percentage distribution in the group. 

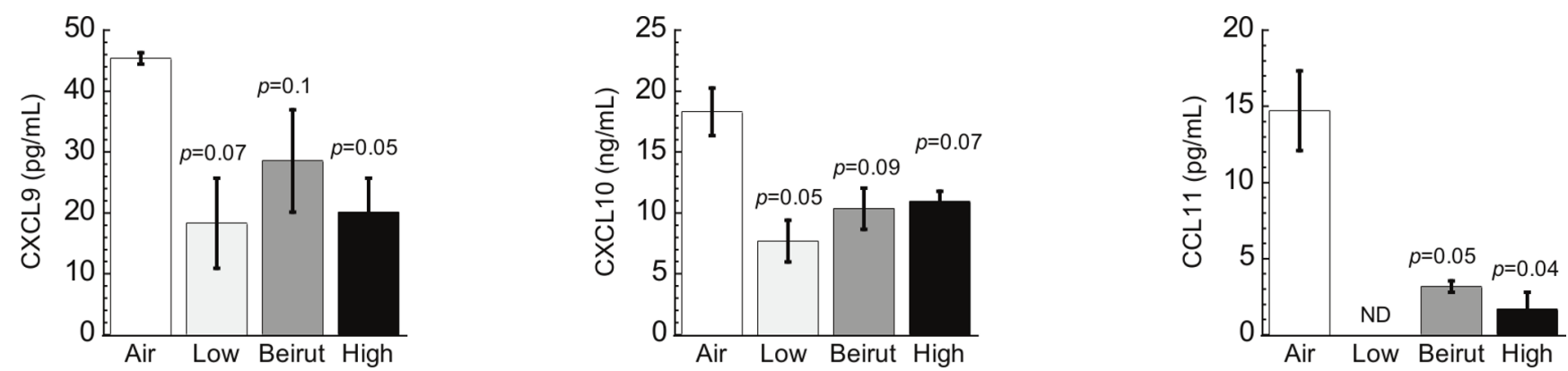

Figure 2 Postchronic exposure analysis of cytokine concentration in bronchoalveolar lavage fluid of murine lungs. No other molecule in the test showed a significant difference. Air: air-exposed control group; Beirut: modified Beirut. Depicted are the results of product 2 . Product 1 remained untested. For each group, error bars represent $S E$ for $n=3$. Student's t-test, assuming equal variance for the distributions and alpha level of 0.05 , was used to compare each group with air control. CXCL9: C-X-C Motif Chemokine Ligand 9; CXCL10: C-X-C Motif Chemokine Ligand 10; CCL11: C-C Motif Chemokine Ligand 11. Above the bars are $p$ values. ND, below the lower limit of detection.

\section{Chronic exposure does not affect lung function}

In mouse models of CS-induced emphysema, emphysematous lesions are indirectly monitored by the deterioration in pulmonary function. The analysis of lung function of mice exposed to product 2 for 6 months showed that lung function is normal as the PV data showed no significant changes to filtered air control mice (online supplementary figure 3 ).

\section{Acute exposure has significant effects on IEG expression}

To identify genetic biomarkers of WP exposure, we used RNAseq analysis to monitor the expression of genes in the lungs after a 1-hour acute exposure to product 2. Furthermore, we determined whether these biomarkers of exposure differed based on the addition of water to the bowl to generate dry smoke. Acute exposures to mainstream WP and dry smoke were similar in TSP to the modified Beirut regimen; however, we found that water accounts for $\sim 60 \%$ of the measured weight in WP smoke (see the Methods section). Values previously reported in comparable experiments showed that water content in dry smoke accounts for $\sim 0.56 \times$ relative to mainstream WP. ${ }^{56}$ Therefore, based on the TSP corrected for water, we estimated that dry WP smoke is $\sim 33 \%$ higher in dry mass. Our results showed that the strongest exposure, based on the number of IEGs upregulated, is dry smoke (141 genes, compared with 49 genes for WP; see figure 3A and online supplementary table 4), which has no means to filter the water-soluble smoke constituents or attenuate smoke temperature. We also found a set of common genes that are differentially expressed in the two acute exposures when compared with the filtered air controls (figure 3A-B). The common genes are potential biomarkers of exposure, while those that show a graded response between dry smoke $>$ WP $>$ air may serve as biomarkers for the strength of exposure. The results indicate that activation or inhibition of genes is enhanced by dry smoke, which is the most harmful exposure as it shows the largest change in gene expression as well as the largest number of genes regulated between the two groups.

Among the DEGs that are common to all experimental groups are those previously identified as IEGs (figure 3B). We observed that CD69 was significantly induced; CD69 is a marker of T cell activation and is considered to be an early response to
A

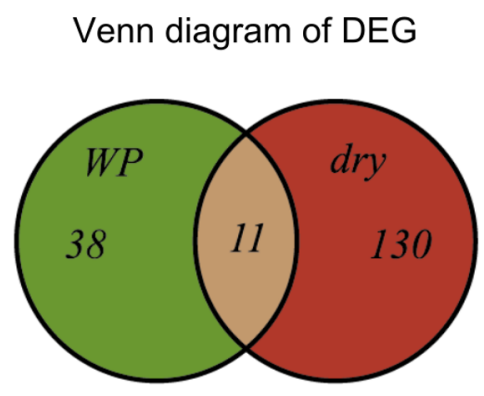

\section{B}

Figure 3 Gene regulation of acute exposure to waterpipe (WP) smoke in murine lungs. Analysis of the lung transcriptome of mice exposed for 1 hour to mainstream WP, dry WP (dry smoke) or filtered air control group. The analysis produced differentially expressed genes (DEG) data sets. The DEGs are cut-off at $\pm 1.2 \log 2$ fold change relative to filtered air control (see details in the Methods section). Depicted is a Venn diagram (A) to represent the relationship of DEGs produced by the WP and dry WP acute exposures. Panel (A) key: brown shade, shared genes between WP and dry WP data sets; green, genes unique to WP data; red, genes unique to dry WP data. The analysis of the shared genes revealed known and novel immediate-early genes (IEGs) with potential to become biomarkers of exposure. Panel (B) shows the gene names and the fold changes (FC) relative to filtered air control of known and novel IEGs. The experiment used product 2 only (product 1 remains untested). $n=3$, WP and filtered air control; $n=2$, dry smoke. 
lymphocyte-mediated inflammation activated by CS. ${ }^{57} 58$ Dusp2 (PAC1) is a dual threonine/tyrosine phosphatase of the Mitogenactivated Protein (MAP) kinases, crucial for the signal transduction function of immune cells. ${ }^{59-62}$ Another previously identified IEG is Verge or APOLD1, which displays modulatory functions of vascular endothelium associated with the development of hypertension in smokers. ${ }^{6364}$ The results indicate that exposure to WP and dry smoke regulates genes known to be IEGs with functions related to the activation of inflammatory and cardiovascular responses.

In addition, a set of genes were identified as novel IEGs that were common among all exposures (figure 3B). The function of the novel IEGs is primarily focused on B cells. Pax5 is a transcriptional regulator that is essential for the commitment of a common lymphoid progenitor towards a B cell lineage. ${ }^{65-67}$ CD79a $(\operatorname{Ig} \alpha)$ is an integral member of the $\mathrm{B}$ cell receptor complex (BCR) that is necessary for the transduction of intracellular signals on antigen binding. ${ }^{68} 69$ Fcer2a (CD23, isoform ' $a$ ') is an IgE receptor that is required in B cells for antigen presentation to T cells. ${ }^{70}$ Two modulators of B cell immunity are also novel IEGs. CD19 amplifies BCR signal transduction, and $\mathrm{Fcmr}$ enhances survival of activated B cells and modulates BCR signal. ${ }^{6475}$ Other common IEGs are described in online supplementary data 1 . The results suggest that certain genes are novel IEGs and are potential genetic biomarkers of exposure to tobacco products. Moreover, the function of IEGs suggests a strong immune response to acute WP exposure.

Based on the results of the comparative analysis of the RNAseq data, a unique set of genes for each experimental group were identified (figure 3A). Therefore, the transcriptomic analysis of IEGs can potentially assign toxicological effects to a specific exposure based on unique changes in gene expression after acute exposures. Simultaneous analysis of the RNAseq data set for the two exposures using IPA canonical pathway analysis separated the two exposures by clusters of genes and defined the activity status of the pathway based on z-scores. This analysis found that WP has an inhibitory effect on 'GP6 Signaling' and 'LXR/RXR' pathways (online supplementary tables 5 and 6) and consists of downregulated genes that increase inflammation (fibrinogen, collagen, laminin) and upregulated genes that suppress inflammation (interleukin-1-receptor-2). ${ }^{76-79}$ In contrast, dry smoke activates the 'PKC $\theta$ Signaling in T Lymphocytes' pathway (online supplementary table 7), which includes genes that function in calcium signalling (CACNA1I, CACNA2D4), ${ }^{80-82}$ cell development (Rac2), ${ }^{83}$ signal transduction (NFKBID), ${ }^{84-86}$ antigen presentation $(\mathrm{H} 2-\mathrm{Q} 6, \mathrm{H} 2-\mathrm{Ob})^{87}$ and antigen receptor function $(\mathrm{Cd} 3 \mathrm{~d}, \mathrm{CD} 28),{ }^{88-91}$ which are of particular relevance for $\mathrm{T}$ cell activation and function. These results indicate a distinctive toxicological signature for each exposure at the level of gene regulation.

\section{DISCUSSION}

The results from our study indicate that there was no significant increase in inflammatory cells and no decrease in pulmonary function after exposure to WP smoke for 6 months. The 6-month exposure length is rarely tested using puffing regimens that are similar to those observed in WP users. ${ }^{48}$ Nonetheless, based on nicotine content, our modified Beirut and high regimens are true representatives of habitual chronic WP smoke usage in humans, while the low regimen is a representative of WP smoking with an electric heat source. ${ }^{50}$ Nicotine in product 2 was used as a reference to estimate nicotine in product 1 (a menthol product), based on a study that showed nicotine in flavoured shisha products is lower than its unflavoured counterpart. ${ }^{92}$ In our study, a low number of replicas of product 1 limited some experiments (BAL, pulmonary function), and in other cases the design of the experiment was developed after the analysis of product 1 exposure (body weight). Furthermore, some techniques (RNAseq, Milliplex) are expensive to perform in our laboratory. Therefore, the discussion is mainly focused on results achieved with product 2 , in instances where product 1 is unavailable.

All puffing regimens, including the higher regimen, were well tolerated in mice as no physiological deterioration was evident in the pulmonary function tests, whereas weight remained unchanged. Previous population studies demonstrated a complex association between smoking and weight, and to date a consensus has not been reached on the cause or directionality of the effect. ${ }^{93-95}$ However, controlled studies using rodents showed that CS and nicotine exposures are associated with weight loss. ${ }^{96-98}$ Moreover, mice exposed to CS of similar TSP concentrations as what were quantified in the current WP study created emphysematous lesions and compromised pulmonary function, leading to the development of COPD. ${ }^{99-102}$ Therefore, our results may be constrained due to the length of exposure and the characteristics of the smoke mixture. However, compared with CS exposures of similar TSP, the WP puffing regimens tested caused less physiological effects. Policymakers should be aware that further research is needed to evaluate the risks of developing or exacerbating COPD, emphysema and cancer.

Nevertheless, exposure to WP presented plausible health risks at the cellular level. The moderate decreases in lymphocyte counts in BAL and in the chemokine concentration observed in some puffing regimens are indicators of immune suppression. Therefore, immune suppression in the chronic WP exposure is plausible and agrees with previously documented nicotine and CO-related effects of CS, ${ }^{103-107}$ mediated by molecular mechanisms, including blockage of $\mathrm{T}$ cell activation ${ }^{108-110}$ and direct inhibition of eosinophil function. ${ }^{111}$ The suppressive effect of the immune response may be associated with the length of the exposure, as previously noted in a study that revealed inflammation in response to shorter exposures to WP. ${ }^{112-114}$ Indeed, we observed an inflammatory effect by acute exposure. Further molecular studies will determine if the immune modulation by chronic exposure to WP is similar to exposure to CS. ${ }^{115-118}$ For example, a test for the compromised function of macrophages as previously reported in the context of CS is needed. ${ }^{119}$ Future experiments will clarify the clinical relevance of the immune suppression by WP, for example, using animal models developed in the laboratory to determine bacterial and viral clearance. ${ }^{120} 121$ A limitation of our work is the use of female mice only. Previous research showed gender-specific health effects and gender differences in the prevalence of tobacco use. ${ }^{114} 122123$ Nevertheless, our results imply that WP users may experience an increased risk of developing severe lung infections and cancer, analogous to what is experienced by cigarette users. Future experiments will inform public health policies aimed to disseminate this and other information regarding health risks associated with WP use. ${ }^{124-126}$

In our research, we identified IEGs in murine lungs expressed after acute exposure to dry smoke and WP mainstream smoke from product 2. Previous research showed that traditional tobacco exposure biomarkers measured immediately after acute exposure in humans were sensitive to detect toxicity differences between tobacco products, in a model dubbed 'boost' measurement paradigm. ${ }^{127}$ In support of the 'boost' paradigm at the gene regulation level, we observed that the activation of IEGs is rapid, as 1 hour of exposure is sufficient for gene regulation. ${ }^{128-130}$ 
The robust differences support the finding that the IEG response is attractive for transcriptional biomarker discovery. ${ }^{131}$ The harmfulness of exposure, based on the number of IEGs per group, follows the trend, dry smoke $>$ WP $>$ air. Such trend demonstrates that dry smoke is most toxic, while water in the WP reduces some combustion components in smoke and decreases smoke temperature compared with conventional cigarette combustion. ${ }^{132}{ }^{133}$ Recently, an innovative semiquantitative analysis showed that water filters a minute class of toxicants from mainstream WP smoke and instead water favoured the nucleation of particulates of facile transmembrane transport. ${ }^{134} 135$ However, in our study, the strong agreement between the degree of toxicity and the total number of IEGs may be related to a decrease in temperature and/or lower concentration of the toxicants in mainstream smoke.

The transcriptomics analysis revealed several IEGs common to all exposures, as well as gene expression profiles that characterise each type of exposure, thereby indicating the specificity of the genetic response. Contrary to the immune suppression experienced in the lungs following chronic exposure, the function of common IEGs are, in most cases, transmembrane receptor mediators of immune response, similar to the known physiological and genetic changes observed after acute exposure to CS. ${ }^{106} 136137$ The group of common novel IEGs were found to be strongly associated with B cell immunity. In contrast, a group of genes with functions in $\mathrm{T}$ cell immunity are exclusively

\section{What this paper adds}

\section{What is already known on this subject}

- Health risks are associated with exposure to waterpipe (WP) smoke in animal models and in vitro experiments.

- Prior results revealed an inflammatory response due to shortterm exposures.

- WP smoke contains a larger concentration of toxicants than cigarette smoke, and users believe that water in the WP bowl has a filtering effect.

- Recent evidence suggests that analysis of genes by RNAseq may become a tool for biomarker discovery.

What important gaps in knowledge exist on this topic

- The health consequences of chronic WP use are not well understood.

- In tobacco regulatory science, a current focus is to identify biomarkers of exposure that are specific to WP and other newly modified tobacco products.

- The immediate expression of genes after an acute dose of WP smoke has never been analysed.

\section{What this paper adds}

- We used a standardised WP exposure model that is similar to WP use by humans.

- Herein, we report immune suppression that occurs after chronic exposure to WP.

- Additionally, we showed that global gene regulation is modified by acute exposure to WP and suggest immune cell activation.

- The magnitude of gene regulation is associated with the severity of acute exposure.

- Our results indicate that whole-cell transcript analysis (transcriptome) could be considered an indicator of exposure (biomarker) with specificity to WP and other tobacco products. upregulated in dry smoke exposure, whereas genes with inhibitory function on lung inflammation were found in response to WP exposure. Therefore, IEGs display the potential to differentiate between distinct exposures. In addition, we showed that the magnitude of the modulation of IEGs is generally positively correlated with the harmfulness of the exposure, similar to that observed in the transcriptomics of rats exposed to CS. ${ }^{138}$ Therefore, IEGs showed specificity and dynamic range that are desirable characteristics in a biomarker.

The present research on IEGs after acute WP exposure is the first of its kind and addresses the need for genetic biomarkers that are specifically tailored to WP use. ${ }^{139}$ We adopted previous approaches to show that IEGs may potentially quantify and predict harmful effects in humans, known as biomarkers of potential harm, based on the magnitude and direction of expression. ${ }^{140-142}$ Furthermore, IEG testing in the nasal epithelium and gingiva (the gums) is a promising and non-invasive alternative with clinical relevance. ${ }^{143} 144$ These results emphasise the importance of policies that support the research and development of IEGs as novel non-traditional biomarkers of newly modified tobacco products.

Acknowledgements We want to acknowledge the following personnel from the Centers for Disease Control and Prevention, Tobacco Products Laboratory, in Norcross, Georgia (USA) for their support in draft criticism, guidance during nicotine measurements and generation of the data from nicotine measurements: Liza Valentin-Blasini, Robert Tyx and Clifford Watson. We also acknowledge Dr. Fenna Sille and Dr. Kristal Rychlik at Johns Hopkins University for their technical assistance in the measurement of cytokine levels.

Contributors SB, TS and HRR-C contributed to the conception of the work. HRR-C and TS contributed to the experimental design, implementation, data analysis, data collection and data interpretation. HRR-C, TS, JL and SB contributed to drafting of the paper. VV contributed to RNAseq experiment. BP contributed to computational reduction of RNAseq data and statistical validation of differentially expressed genes. JL, WM, IS and JE contributed to pulmonary function. MCB provided guidance on use of the research-grade WP and manuscript review. YCC, JW and JE contributed to all mice-related activities including mice exposure and organ collection.

Funding This work was supported by the National Institutes of Health under award numbers R01HL134149 (SB) and 3U01ES026721-02S1 (HRR-C).

\section{Competing interests None declared.}

\section{Patient consent for publication Not required.}

Ethics approval This study was approved by the Animal Care and Use Committee (IACUC) at Johns Hopkins University. All animal experiments (methodology and procedures) were performed according to the recommendations and guidelines of the IACUC.

Provenance and peer review Not commissioned; externally peer reviewed. Data availability statement Data are available upon reasonable request.

\section{ORCID iDs}

Hermes Reyes-Caballero http://orcid.org/0000-0001-6815-0468

Bongsoo Park 0000-0003-1720-9567

Jeffrey Loube 0000-0002-3382-0414

lan Sanchez 0000-0002-4357-3728

Vinesh Vinayachandran 0000-0002-2045-6086

Youngshim Choi 0000-0002-0735-6072

Juhyung Woo 0000-0001-6262-8088

Marielle C Brinkman http://orcid.org/0000-0002-4315-649X

Thomas Sussan 0000-0002-5240-4299

Wayne Mitzner 0000-0003-1615-4090

Shyam Biswal 0000-0003-0431-3939

\section{REFERENCES}

1 Maziak W, Ward KD, Afifi Soweid RA, et al. Tobacco smoking using a waterpipe: a re-emerging strain in a global epidemic. Tob Control 2004;13:327-33.

2 Maziak W. The global epidemic of waterpipe smoking. Addict Behav 2011;36:1-5.

3 Jawad M, Charide R, Waziry R, et al. The prevalence and trends of waterpipe tobacco smoking: a systematic review. PLoS One 2018;13:e0192191. 
4 Soulakova JN, Pham T, Owens VL, et al. Prevalence and factors associated with use of hookah tobacco among young adults in the U.S. Addict Behav 2018;85:21-5.

5 Jawad M, El Kadi L, Mugharbil S, et al. Waterpipe tobacco smoking legislation and policy enactment: a global analysis. Tob Control 2015;24 Suppl 1(Suppl 1):i60-5.

6 Bhatnagar A, Maziak W, Eissenberg T, et al. Water pipe (Hookah) smoking and cardiovascular disease risk: a scientific statement from the American heart association. Circulation 2019;139:e917-36.

7 Awan KH, Siddiqi K, Patil S, et al. Assessing the Effect of Waterpipe Smoking on Cancer Outcome - a Systematic Review of Current Evidence. Asian Pac J Cancer Prev 2017;18:495-502.

8 Montazeri Z, Nyiraneza C, El-Katerji H, et al. Waterpipe smoking and cancer: systematic review and meta-analysis. Tob Control 2017;26:92-7.

9 Lai HTM, Koriyama C, Tokudome S, et al. Waterpipe tobacco smoking and gastric cancer risk among Vietnamese men. PLoS One 2016;11:e0165587.

10 Mamtani R, Cheema S, Sheikh J, et al. Cancer risk in waterpipe smokers: a metaanalysis. Int J Public Health 2017;62:73-83.

11 Saffar Soflaei S, Darroudi S, Tayefi M, et al. Hookah smoking is strongly associated with diabetes mellitus, metabolic syndrome and obesity: a population-based study. Diabetol Metab Syndr 2018;10.

12 Waked M, Khayat G, Salameh P. Chronic obstructive pulmonary disease prevalence in Lebanon: a cross-sectional descriptive study. Clin Epidemiol 2011;3:315-23.

13 Aboaziza E, Eissenberg T. Waterpipe tobacco smoking: what is the evidence that it supports nicotine/tobacco dependence? Tob Control 2015;24 Suppl 1(Suppl 1):i44-53.

14 Asfar T, Al Ali R, Rastam S, et al. Behavioral cessation treatment of waterpipe smoking: the first pilot randomized controlled trial. Addict Behav 2014;39:1066-74.

15 Shishani K, Odom-Maryon T, Roll JM. A randomized clinical trial to evaluate the efficacy of contingency management for treatment of waterpipe tobacco addiction. Am J Addict 2018;27:202-9.

16 Leavens ELS, Meier E, Tackett AP, et al. The impact of a brief cessation induction intervention for waterpipe tobacco smoking: a pilot randomized clinical trial. Addict Behav 2018;78:94-100.

17 Bahelah R, Ward KD, Ben Taleb Z, et al. Determinants of progression of nicotine dependence symptoms in adolescent waterpipe smokers. Tob Control 2019;28:254-60

18 Ramji R, Arnetz BB, Nilsson M, et al. Waterpipe use in adolescents in northern Sweden: association with mental well-being and risk and health behaviours. Scand J Public Health 2018:46:867-76.

19 Marusich JA, Wiley JL, Silinski MAR, et al. Comparison of cigarette, little cigar, and waterpipe tobacco smoke condensate and e-cigarette aerosol condensate in a selfadministration model. Behav Brain Res 2019;372:112061.

20 Shihadeh A, Schubert J, Klaiany J, et al. Toxicant content, physical properties and biological activity of waterpipe tobacco smoke and its tobacco-free alternatives. Tob Control 2015;24(Suppl 1):i22-30

21 Jawad M, Eissenberg T, Salman R, et al. Toxicant inhalation among singleton waterpipe tobacco users in natural settings. Tob Control 2019;28:181-8.

22 Walters MS, Salit J, Ju JH, et al. Waterpipe smoking induces epigenetic changes in the small airway epithelium. PLoS One 2017;12:e0171112.

23 Szyfter K, Napierala M, Florek E, et al. Molecular and health effects in the upper respiratory tract associated with tobacco smoking other than cigarettes. Int J Cancer 2019;144:2635-43.

24 Rammah M, Dandachi F, Salman R, et al. In vitro effects of waterpipe smoke condensate on endothelial cell function: a potential risk factor for vascular disease. Toxicol Lett 2013;219:133-42.

25 Rammah M, Dandachi F, Salman R, et al. In vitro cytotoxicity and mutagenicity of mainstream waterpipe smoke and its functional consequences on alveolar type II derived cells. Toxicol Lett 2012;211:220-31.

26 Alsaad AM, Al-Arifi MN, Maayah ZH, et al. Genotoxic impact of long-term cigarette and waterpipe smoking on DNA damage and oxidative stress in healthy subjects. Toxicol Mech Methods 2019:29:119-27.

27 Strimbu K, Tavel JA. What are biomarkers? Curr Opin HIV AIDS 2010;5:463-6.

28 FDA. Biomarkers at FDA, 2018. Available: https://www.fda.gov/ScienceResearch/ AboutScienceResearchatFDA/ucm519362.htm [Accessed 20 Dec 2018].

29 Peck MJ, Sanders EB, Scherer G, et al. Review of biomarkers to assess the effects of switching from cigarettes to modified risk tobacco products. Biomarkers 2018;23:213-44.

30 Chang CM, Edwards SH, Arab A, et al. Biomarkers of tobacco exposure: summary of an FDA-Sponsored public workshop. Cancer Epidemiol Biomarkers Prev 2017:26:291-302

31 Brinkman MC, Kim H, Gordon SM, et al. Design and validation of a Research-Grade waterpipe equipped with puff topography analyzer. NICTOB 2016;18:785-93.

32 Shihadeh A, Azar S, Antonios C, et al. Towards a topographical model of narghile water-pipe café smoking: a pilot study in a high socioeconomic status neighborhood of Beirut, Lebanon. Pharmacol Biochem Behav 2004;79:75-82

33 Calafat AM, Polzin GM, Saylor J, et al. Determination of TAR, nicotine, and carbon monoxide yields in the mainstream smoke of selected international cigarettes. Tob Control 2004;13:45-51.
34 Hensel EC, Eddingsaas NC, DiFrancesco AG, et al. Framework to estimate total particulate mass and nicotine delivered to E-cig users from natural environment monitoring data. Sci Rep 2019:9:8752.

35 Sussan TE, Gajghate $\mathrm{S}$, Chatterjee $\mathrm{S}$, et al. Nrf2 reduces allergic asthma in mice through enhanced airway epithelial cytoprotective function. Am J Physiol Lung Cell Mol Physiol 2015;309:L27-L36.

36 Rangasamy T, Cho CY, Thimmulappa RK, et al. Genetic ablation of Nrf2 enhances susceptibility to cigarette smoke-induced emphysema in mice. J Clin Invest 2004;114:1248-59.

37 Saltini C, Hance AJ, Ferrans VJ, et al. Accurate quantification of cells recovered by bronchoalveolar lavage. Am Rev Respir Dis 1984;130:650-8.

38 Le Guezennec X, Quah J, Tong L, et al. Human tear analysis with miniaturized multiplex cytokine assay on "wall-less" 96-well plate. Mol Vis 2015;21:1151-61.

39 Jing W, Cui J, Fu Y, et al. A novel method for multiple cytokines/chemokines DropArray assay in $5 \mu \mathrm{L}$ of bronchoalveolar lavage fluid (BALF) in mice. Sensors and Actuators B: Chemical 2017;242:195-201.

40 Limjunyawong N, Fallica J, Ramakrishnan A, et al. Phenotyping Mouse Pulmonary Function <em>In Vivo</em> with the Lung Diffusing Capacity. JoVE 2015;(95).

41 Fallica J, Das S, Horton M, et al. Application of carbon monoxide diffusing capacity in the mouse lung. J App/ Physio/ 2011;110:1455-9.

42 Limjunyawong N, Fallica J, Horton MR, et al. Measurement of the pressure-volume curve in mouse lungs. JoVE 2015;(95) (Published Online First: 5 Feb 2015).

43 Soutiere SE, Mitzner W. On defining total lung capacity in the mouse. J Appl Physiol 2004:96:1658-64.

44 Dobin A, Davis CA, Schlesinger F, et al. Star: ultrafast universal RNA-seq aligner. Bioinformatics 2013;29:15-21.

45 Risso D, Ngai J, Speed TP, et al. Normalization of RNA-Seq data using factor analysis of control genes or samples. Nat Biotechnol 2014:32:896-902.

46 Robinson MD, McCarthy DJ, Smyth GK. edgeR: a Bioconductor package for differential expression analysis of digital gene expression data. Bioinformatics 2010;26:139-40

47 Brinkman M, Klerx W, Shihadeh A, et al. Applicability and adaptability of the who tobacco laboratory network standard operating procedures for cigarettes to waterpipe tobacco. In: WHO. Geneva: WHO study group on the scientific basis of tobacco product regulation: sixth report of a WHO study group, 2017.

48 Rezk-Hanna M, Benowitz NL. Cardiovascular effects of Hookah smoking: potential implications for cardiovascular risk. Nicotine Tob Res 2018.

49 Shihadeh A. Investigation of mainstream smoke aerosol of the argileh water pipe. Food Chem Toxicol 2003:41:143-52.

50 Brinkman MC, Kim H, Buehler SS, et al. Evidence of compensation among waterpipe smokers using harm reduction components. Tob Control 2020;29:15-23.

51 Liu M, Guo S, Stiles JK. The emerging role of CXCL10 in cancer (review). Oncol Lett 2011:2:583-9.

52 Belperio JA, Keane MP, Burdick MD, et al. Role of CXCL9/CXCR3 chemokine biology during pathogenesis of acute lung allograft rejection. $J$ Immunol 2003:171:4844-52.

53 Jing H, Liu L, Zhou J, et al. Inhibition of C-X-C motif chemokine 10 (CXCL10) protects mice from cigarette smoke-induced chronic obstructive pulmonary disease. Med Sci Monit 2018;24:5748-53.

54 Nie L, Xiang R, Zhou W, et al. Attenuation of acute lung inflammation induced by cigarette smoke in CXCR3 knockout mice. Respir Res 2008;9:82

55 Bandeira-Melo C, Weller PF. Eosinophils and cysteinyl leukotrienes. Prostaglandins Leukot Essent Fatty Acids 2003;69:135-43.

56 Schubert J, Kappenstein O, Luch A, et al. Analysis of primary aromatic amines in the mainstream waterpipe smoke using liquid chromatography-electrospray ionization tandem mass spectrometry. J Chromatogr A 2011;1218:5628-37.

57 Ziegler SF, Ramsdell F, Alderson MR. The activation antigen CD69. Stem Cells 1994; 12:456-65

58 Tsuyusaki J, Kuroda F, Kasuya Y, et al. Cigarette smoke-induced pulmonary inflammation is attenuated in CD69-deficient mice. Journal of Receptors and Signal Transduction 2011;31:434-9.

59 Rohan PJ, Davis P, Moskaluk CA, et al. Pac-1: a mitogen-induced nuclear protein tyrosine phosphatase. Science 1993:259:1763-6.

60 Grumont RJ, Rasko JE, Strasser A, et al. Activation of the mitogen-activated protein kinase pathway induces transcription of the PAC-1 phosphatase gene. Mol Cell Biol 1996;16:2913-21.

61 Jeffrey KL, Brummer T, Rolph MS, et al. Positive regulation of immune cell function and inflammatory responses by phosphatase PAC-1. Nat Immunol 2006;7:274-83.

62 Huang C-Y, Tan T-H, DUSPs TTH. Dusps, to MAP kinases and beyond. Cell BiosCi $2012: 2$

63 Regard JB, Scheek S, Borbiev T, et al. Verge: a novel vascular early response gene. J Neurosci 2004:24:4092-103.

64 Sung YJ, Winkler TW, de Las Fuentes L, et al. A large-scale Multi-ancestry genomewide study accounting for smoking behavior identifies multiple significant loci for blood pressure. Am J Hum Genet 2018;102:375-400.

65 Raver RM, Panfil AR, Hagemeier SR, et al. The B-cell-specific transcription factor and master regulator Pax 5 promotes Epstein-Barr virus latency by negatively regulating the viral immediate early protein BZLF1. J Virol 2013;87:8053-63. 
66 Cobaleda C, Schebesta A, Delogu A, et al. Pax5: the guardian of B cell identity and function. Nat Immunol 2007:8:463-70.

67 Sigvardsson M. Molecular regulation of differentiation in early B-lymphocyte development. Int J Mo/ Sci 2018;19:1928.

68 Treanor B. B-Cell receptor: from resting state to activate. Immunology 2012;136:21-7.

69 Monroe JG. ITAM-mediated tonic signalling through pre-BCR and BCR complexes. Nat Rev Immunol 2006:6:283-94.

70 Kikutani $H$, Suemura M, Owaki $H$, et al. Fc epsilon receptor, a specific differentiation marker transiently expressed on mature B cells before isotype switching. J Exp Med 1986;164:1455-69.

71 Kehry MR, Yamashita LC. Low-Affinity IgE receptor (CD23) function on mouse B cells: role in IgE-dependent antigen focusing. Proc Natl Acad Sci U S A 1989:86:7556-60.

72 Poe JC, Hasegawa M, Tedder TF. Cd19, CD21, and CD22: multifaceted response regulators of B lymphocyte signal transduction. Int Rev Immunol 2001;20:739-62.

73 Choi S-C, Wang H, Tian L, et al. Mouse IgM Fc receptor, FCMR, promotes $B$ cell development and modulates antigen-driven immune responses. J.i. 2013;190:987-96.

74 Liu J, Wang Y, Xiong E, et al. Role of the IgM Fc receptor in immunity and tolerance. Front Immunol 2019;10.

75 Wang H, Coligan JE, Morse HC. Emerging functions of natural IgM and its Fc receptor FCMR in immune homeostasis. Front Immunol 2016;7(Suppl 1):99.

76 Christie PE, Jonas M, Tsai CH, et al. Increase in laminin expression in allergic airway remodelling and decrease by dexamethasone. Eur Respir J 2004;24:107-15.

77 Nomura A, Uchida Y, Sakamoto T, et al. Increases in collagen type I synthesis in asthma: the role of eosinophils and transforming growth factor-beta. Clin Exp Allergy 2002;32:860-5.

78 Jousilahti P, Salomaa V, Hakala K, et al. The association of sensitive systemic inflammation markers with bronchial asthma. Annals of Allergy, Asthma \& Immunology 2002:89:381-5.

79 Peters VA, Joesting JJ, Freund GG. II-1 receptor 2 (IL-1R2) and its role in immune regulation. Brain Behav Immun 2013:32:1-8.

80 Feske $\mathrm{S} . \mathrm{Ca}(2+)$ influx in T cells: how many $\mathrm{ca}(2+)$ channels? Front Immunol 2013:4:99.

81 Buchanan PJ, McCloskey KD, Ca MKD. Ca channels and cancer: canonical functions indicate benefits of repurposed drugs as cancer therapeutics. Eur Biophys $J$ 2016:45:621-33.

82 Dolphin AC. Voltage-gated calcium channel $\alpha_{2} \delta$ subunits: an assessment of proposed novel roles. F1000Res 2018;7. 10.12688/f1000research.16104.1. [Epub ahead of print: 21 Nov 2018]. F1000 Faculty Rev-830.

83 Dumont C, Corsoni-Tadrzak A, Ruf S, et al. Rac GTPases play critical roles in early T-cell development. Blood 2009;113:3990-8.

84 Hayden MS, West AP, Ghosh S. Nf-kappaB and the immune response. Oncogene 2006:25:6758-80

85 Viatour P, Merville M-P, Bours V, et al. Phosphorylation of NF-kappaB and IkappaB proteins: implications in cancer and inflammation. Trends Biochem SCi 2005;30:43-52.

86 Tergaonkar V, Correa RG, Ikawa M, et al. Distinct roles of IkappaB proteins in regulating constitutive NF-kappaB activity. Nat Cell Biol 2005;7:921-3.

87 Wieczorek M, Abualrous ET, Sticht J, et al. Major histocompatibility complex (MHC) class I and MHC class II proteins: conformational plasticity in antigen presentation. Front Immunol 2017:8:292-92.

88 Kuhns MS, Badgandi HB. Piecing together the family portrait of TCR-CD3 complexes Immunol Rev 2012;250:120-43.

89 Linsley PS, Ledbetter JA. The role of the CD28 receptor during T cell responses to antigen. Annu Rev Immunol 1993;11:191-212.

90 Beyersdorf N, Kerkau T, Hünig T. Cd28 co-stimulation in T-cell homeostasis: a recent perspective. Immunotargets Ther 2015;4:111-22.

91 Birnbaum ME, Berry R, Hsiao Y-S, et al. Molecular architecture of the $\alpha \beta$ T cell receptor-CD3 complex. Proc Natl Acad Sci U S A 2014;111:17576-81.

92 Farag MA, Elmassry MM, El-Ahmady SH. The characterization of flavored hookahs aroma profile and in response to heating as analyzed via headspace solid-phase microextraction (SPME) and chemometrics. Sci Rep 2018;8:17028.

93 Dare S, Mackay DF, Pell JP. Relationship between smoking and obesity: a crosssectional study of 499,504 middle-aged adults in the UK general population. PLOS One 2015;10:e0123579-e79.

94 Kim Y, Jeong SM, Yoo B, et al. Associations of smoking with overall obesity, and central obesity: a cross-sectional study from the Korea National health and nutrition examination survey (2010-2013). Epidemiol Health 2016;38:e2016020.

95 Ward KD, Ahn S, Mzayek F, et al. The relationship between waterpipe smoking and body weight: population-based findings from Syria. Nicotine Tob Res 2015:17:34-40.

96 Chen $\mathrm{H}$, Hansen MJ, Jones JE, et al. Detrimental metabolic effects of combining longterm cigarette smoke exposure and high-fat diet in mice. Am J Physiol Endocrinol Metab 2007:293:E1564-E1571.

97 Phillips B, Veljkovic E, Boué SOviedo A, Elamin A, et al. An 8-Month systems toxicology Inhalation/Cessation study in ApoE-/- mice to investigate cardiovascular and respiratory exposure effects of a candidate modified risk tobacco product, THS 2.2, compared with conventional cigarettes. Toxicol Sci 2016;149:411-32.

98 Mangubat M, Lutfy $\mathrm{K}$, Lee ML, et al. Effect of nicotine on body composition in mice. J Endocrinol 2012:212:317-26.

99 Ghorani V, Boskabady MH, Khazdair MR, et al. Experimental animal models for COPD: a methodological review. Tob Induc Dis 2017;15:25.

100 Robison P, Sussan TE, Chen H, et al. Impaired calcium signaling in muscle fibers from intercostal and foot skeletal muscle in a cigarette smoke-induced mouse model of COPD. Muscle Nerve 2017;56:282-91.

101 Sussan TE, Rangasamy T, Blake DJ, et al. Targeting Nrf2 with the triterpenoid CDDOimidazolide attenuates cigarette smoke-induced emphysema and cardiac dysfunction in mice. Proc Natl Acad Sci U S A 2009;106:250-5.

102 Rinaldi M, Maes K, De Vleeschauwer S, et al. Long-Term nose-only cigarette smoke exposure induces emphysema and mild skeletal muscle dysfunction in mice. Dis Model Mech 2012:5:333-41.

103 Nizri E, Irony-Tur-Sinai M, Lory 0 , et al. Activation of the cholinergic antiinflammatory system by nicotine attenuates neuroinflammation via suppression of Th1 and Th17 responses. J Immunol 2009;183:6681-8.

104 Fujii T, Mashimo M, Moriwaki Y, et al. Expression and function of the cholinergic system in immune cells. Front Immunol 2017;8.

105 Ren C, Li X-H, Wang S-B, et al. Activation of central alpha 7 nicotinic acetylcholine receptor reverses suppressed immune function of $\mathrm{T}$ lymphocytes and protects against sepsis lethality. Int J Biol Sci 2018;14:748-59.

106 van der Vaart H, Postma DS, Timens W, et al. Acute effects of cigarette smoke on inflammation and oxidative stress: a review. Thorax 2004;59:713-21.

107 Rémy S, Blancou P, Tesson L, et al. Carbon monoxide inhibits TLR-induced dendritic cell immunogenicity. J Immunol 2009;182:1877-84.

108 Fillatreau S, Gray D, Anderton SM. Not always the bad guys: B cells as regulators of autoimmune pathology. Nat Rev Immunol 2008;8:391-7.

109 Piccirillo CA, Shevach EM. Naturally-Occurring CD4+CD25+ immunoregulatory T cells: central players in the arena of peripheral tolerance. Semin Immuno/ 2004;16:81-8.

110 Nouri-Shirazi M, Guinet E. Evidence for the immunosuppressive role of nicotine on human dendritic cell functions. Immunology 2003;109:365-73.

111 Blanchet M-R, Langlois A, Israël-Assayag E, et al. Modulation of eosinophil activation in vitro by a nicotinic receptor agonist. J Leukoc Biol 2007;81:1245-51.

112 Khabour OF, Alzoubi KH, Al-Sawalha N, et al. The effect of chronic exposure to waterpipe tobacco smoke on airway inflammation in mice. Life Sci 2018;200:110-4.

113 Al-Sawalha NA, Migdadi Ala'a M, Alzoubi KH, et al. Effect of waterpipe tobacco smoking on airway inflammation in murine model of asthma. Inhal Toxicol 2017:29:46-52

114 Khan NA, Sundar IK, Rahman I. Strain- and sex-dependent pulmonary toxicity of waterpipe smoke in mouse. Physiol Rep 2018;6:e13579.

115 Mehta H, Nazzal K, Sadikot RT. Cigarette smoking and innate immunity. Inflamm Res 2008; 57:497-503.

116 Qiu F, Liang C-L, Liu H, et al. Impacts of cigarette smoking on immune responsiveness: up and Down or upside down? Oncotarget 2016;8:268-84.

117 John G, Kohse K, Orasche J, et al. The composition of cigarette smoke determines inflammatory cell recruitment to the lung in COPD mouse models. Clin Sci 2014;126:207-21.

118 Strzelak A, Ratajczak A, Adamiec A, et al. Tobacco smoke induces and alters immune responses in the lung triggering inflammation, allergy, asthma and other lung diseases: a mechanistic review. Int J Environ Res Public Health 2018;15. 10.3390/ ijerph15051033. [Epub ahead of print: 21 May 2018].

119 Kulkarni R, Jeyaseelan S. Aiding and abetting the enemy: nicotine impairs the macrophage defense against MTB. Am J Respir Cell Mol Biol 2017;57:263-4.

120 Sussan TE, Gajghate S, Thimmulappa RK, et al. Exposure to electronic cigarettes impairs pulmonary anti-bacterial and anti-viral defenses in a mouse model. PLoS One 2015:10:e0116861.

121 Harvey CJ, Thimmulappa RK, Sethi S, et al. Targeting Nrf2 signaling improves bacterial clearance by alveolar macrophages in patients with COPD and in a mouse model. Sci Trans/ Med 2011;3:78ra32.

122 Danaei M, Jabbarinejad-Kermani A, Mohebbi E, et al. Waterpipe tobacco smoking prevalence and associated factors in the Southeast of Iran. Addict Health 2017:9:72-80

123 Allen AM, Oncken C, Hatsukami D, Women HD. Women and smoking: the effect of gender on the epidemiology, health effects, and cessation of smoking. Curr Addict Rep 2014:1:53-60.

124 Bagaitkar J, Demuth DR, Scott DA. Tobacco use increases susceptibility to bacterial infection. Tob Induc Dis 2008:4:12.

125 Straus WL, Plouffe JF, File TM, et al. Risk factors for domestic acquisition of Legionnaires disease. Ohio Legionnaires disease group. Arch Intern Med 1996;156:1685-92.

126 Shearston J, Lee L, Eazor J, et al. Effects of exposure to direct and secondhand hookah and e-cigarette aerosols on ambient air quality and cardiopulmonary health in adults and children: protocol for a panel study. BMJ Open 2019:9:e029490.

127 Brinkman MC, Chuang JC, Gordon SM, et al. Exposure to and deposition of fine and ultrafine particles in smokers of menthol and nonmenthol cigarettes. Inhal Toxicol 2012;24:255-69.

128 Fowler T, Sen R, Roy AL. Regulation of primary response genes. Mo/ Cell 2011;44:348-60. 
129 Bahrami S, Drabløs F. Gene regulation in the immediate-early response process. Adv Biol Regul 2016:62:37-49.

130 Tullai JW, Schaffer ME, Mullenbrock S, et al. Immediate-Early and delayed primary response genes are distinct in function and genomic architecture. J Biol Chem 2007;282:23981-95.

131 Pfaffl MW. Transcriptional biomarkers. Methods 2013;59:1-2.

132 Torikai K, Torikaiu K, Uwano Y, Nakamori T, et al. Study on tobacco components involved in the pyrolytic generation of selected smoke constituents. Food Chem Toxicol 2005;43:559-68.

133 Schubert J, Heinke V, Bewersdorff J, et al. Waterpipe smoking: the role of humectants in the release of toxic carbonyls. Arch Toxicol 2012;86:1309-16.

134 Perraud V, Lawler MJ, Malecha KT, et al. Chemical characterization of nanoparticles and volatiles present in mainstream hookah smoke. Aerosol Sci Technol 2019.

135 Amornwachirabodee K, Khramchantuk S, Pienpinijtham P, et al. Enhancing passive transport of Micro/Nano particles into cells by oxidized carbon black. ACS Omega 2018;3:6833-40.

136 Billatos E, Faiz A, Gesthalter Y, et al. Impact of acute exposure to cigarette smoke on airway gene expression. Physiol Genomics 2018;50:705-13.

137 Chaouachi K. Use \& Misuse of Water-filtered Tobacco Smoking Pipes in the World. Consequences for Public Health, Research \& Research Ethics. Open Med Chem J 2015;9:1-12.
138 Gebel S, Gerstmayer B, Kuhl P, et al. The kinetics of transcriptomic changes induced by cigarette smoke in rat lungs reveals a specific program of defense, inflammation, and circadian clock gene expression. Toxicol Sci 2006;93:422-31.

139 Sutfin EL, Soule EK, McKelvey K, et al. Implications and challenges for implementation of the FDA's final deeming rule for waterpipe tobacco. Tob Control 2018;27:347-51.

140 Zhang JD, Küng E, Boess F, et al. Pathway reporter genes define molecular phenotypes of human cells. BMC Genomics 2015;16:342.

141 Chang CM, Cheng YC, Cho M, et al. Biomarkers of potential harm: summary of an FDA-Sponsored public workshop. Nicotine Tob Res 2017 (Published Online First: 19 Dec 2017).

142 Zhang JD, Berntenis N, Roth A, et al. Data mining reveals a network of earlyresponse genes as a consensus signature of drug-induced in vitro and in vivo toxicity. Pharmacogenomics J 2014;14:208-16.

143 Hijazi K, Malyszko B, Steiling K, et al. Tobacco-Related alterations in airway gene expression are rapidly reversed within weeks following smoking-cessation. Sci Rep 2019;9.

144 Wang Y, Tatakis D. Smoking alters the normal transcriptome of healthy human gingiva. Tob Induc Dis 2018;16. 